Buletin Ilmiah Math. Stat. dan Terapannya (Bimaster)

Volume 08, No. 4 (2019), hal 729 - 736.

\title{
FAKTOR-FAKTOR YANG MEMENGARUHI BESAR KLAIM ASURANSI JIWA DENGAN MENGGUNAKAN MODEL REGRESI TOBIT
}

\author{
Adharty Pratiwi Sembiring
}

\begin{abstract}
INTISARI
Analisis regresi tobit merupakan analisis regresi yang dapat digunakan untuk variabel terikat yang sebagian datanya bernilai nol (diskrit) dan sebagian data yang lain memiliki nilai tertentu yang bervariasi (kontinu). Penelitian ini bertujuan untuk membentuk model regresi Tobit dan menentukan faktor yang memengaruhi besar klaim dari klaim asuransi jiwa. Data yang digunakan dalam penelitian berupa data besar klaim asuransi $(Y)$, produk asuransi $\left(X_{1}\right)$, cara pembayaran premi $\left(X_{2}\right)$, masa asuransi $\left(X_{3}\right)$, besar pembayaran premi $\left(X_{4}\right)$ dan masa pembayaran premi $\left(X_{5}\right)$. Penduga parameter pada model regresi Tobit menggunakan metode Maximum Likelihood dan penentuan model terbaik dihitung menggunakan metode Akaike Information Criterion (AIC). Dari lima variabel bebas yang digunakan, hanya produk asuransi $\left(X_{1}\right)$ dan masa asuransi $\left(X_{3}\right)$ yang memengaruhi besar klaim asuransi jiwa. Adapun model akhir regresi Tobit yang diperoleh $Y^{*}=-45.998 .539-3.826 .493,0 X_{1}-1.818 .050,0 X_{3}$ dengan nilai $R^{2}$ sebesar $1,76 \%$.
\end{abstract}

Kata Kunci: Regresi Tobit, Maximum Likelihood, Akaike Information Criterion.

\section{PENDAHULUAN}

Analisis regresi merupakan alat statistik yang bermanfaat untuk mengetahui hubungan antara dua variabel atau lebih, sehingga salah satu variabel dapat diduga dari variabel lainnya. Analisis regresi yang umum digunakan adalah analisis regresi linear. Dalam analisis regresi linear, variabel terikat yang digunakan minimal berskala pengukuran interval. Namun dalam beberapa kasus terdapat variabel terikat dengan data campuran. Variabel terikat dengan data campuran merupakan variabel terikat yang sebagian datanya bernilai nol dan sebagian data yang lain memiliki nilai tertentu yang bervariasi, sehingga data tersebut termasuk data tersensor [1]. Model khusus yang dapat digunakan untuk menangani data tersensor yaitu model regresi Tobit [2].

Pada pemodelan ini observasi yang bernilai nol tetap disertakan dalam persamaan regresi sehingga variabel responnya merupakan kumpulan dari observasi yang bernilai nol dan observasi yang tidak bernilai nol. Model regresi Tobit mengasumsikan bahwa variabel-variabel bebas tidak terbatas nilainya (Non-Censored) hanya variabel terikat yang terbatas nilainya (Censored) [3].

Tujuan penelitian ini adalah untuk membentuk model regresi Tobit pada data besar klaim asuransi jiwa dan menentukan faktor yang memengaruhi besar klaim asuransi jiwa. Data yang digunakan dalam penelitian ini berupa data besar klaim asuransi jiwa $(\mathrm{Y})$, produk asuransi $\left(\mathrm{X}_{1}\right)$, cara pembayaran premi $\left(\mathrm{X}_{2}\right)$, masa asuransi $\left(\mathrm{X}_{3}\right)$, besar pembayaran premi $\left(\mathrm{X}_{4}\right)$ dan masa pembayaran premi $\left(\mathrm{X}_{5}\right)$. Penduga parameter pada model regresi Tobit menggunakan metode Maximum Likelihood dan penentuan model terbaik dihitung menggunakan metode Akaike Information Criterion (AIC).

Analisis data dimulai dengan membentuk model persamaan dan mengasumsikan semua variabel berpengaruh terhadap model. Langkah selanjutnya yaitu melakukan uji signifikansi parameter model, kemudian menghitung nilai AIC dan $\mathrm{R}^{2}$ dari masing-masing model regresi Tobit yang dapat terbentuk dari banyaknya penduga parameter yang signifikan. Selanjutnya menginterpretasikan faktor-faktor apa saja yang memengaruhi terjadinya klaim dari nilai yang diperoleh. 


\section{REGRESI TOBIT}

Regresi Tobit merupakan analisis regresi dimana nilai variabel terikatnya memiliki nilai masukan berupa sebagian data diskrit (bernilai nol) dan sebagian lagi berupa data kontinu (bernilai tidak nol) [4]. Model yang mendasari regresi Tobit secara umum sebagai berikut [5]:

$$
y_{i}=\left\{\begin{array}{c}
y_{i}^{*}, y_{i}^{*}>0 \\
0, y_{i}^{*} \leq 0
\end{array}\right.
$$

Dengan $y_{i}^{*}$ adalah variabel terikat dengan persamaan sebagai berikut:

$$
\begin{aligned}
y_{i}^{*} & =\beta_{0}+\beta_{1} x_{1 i}+\beta_{2} x_{2 i}+\cdots+\beta_{k} x_{k i}+u_{i} \\
& =1 \beta_{0}+x_{1 i} \beta_{1}+x_{2 i} \beta_{2}+\cdots+x_{k i} \beta_{k}+u_{i} \\
& =\left[\begin{array}{ccccc}
1 & x_{11} & x_{21} & \ldots & x_{k 1} \\
1 & x_{12} & x_{22} & \ldots & x_{k 2} \\
\vdots & \vdots & \vdots & \vdots & \vdots \\
1 & x_{1 i} & x_{2 i} & \ldots & x_{k i}
\end{array}\right]\left[\begin{array}{c}
\beta_{0} \\
\beta_{1} \\
\beta_{2} \\
\vdots \\
\beta_{k}
\end{array}\right]+\left[\begin{array}{c}
u_{1} \\
u_{2} \\
u_{3} \\
\vdots \\
u_{i}
\end{array}\right] \\
& =\left[\begin{array}{cccc}
1 & 1 & \ldots & 1 \\
x_{11} & x_{12} & \ldots & x_{1 i} \\
x_{21} & x_{22} & \ldots & x_{2 i} \\
\vdots & \vdots & \vdots & \vdots \\
x_{k 1} & x_{k 2} & \ldots & x_{k i}
\end{array}\right]\left[\begin{array}{c}
\beta_{0} \\
\beta_{1} \\
\beta_{2} \\
\vdots \\
\beta_{k}
\end{array}\right]+\left[\begin{array}{c}
u_{1} \\
u_{2} \\
u_{3} \\
\vdots \\
u_{i}
\end{array}\right] \\
y_{i}^{*} & =x_{i}^{\prime} \beta+u_{i}
\end{aligned}
$$

dimana:

$y_{i}^{*}$ : adalah nilai variabel terikat yang sebenarnya

$x_{i}^{\prime}$ : transpose dari $x_{i}$

$\beta$ : parameter yang berukuran $\mathrm{k} \times 1$

$u_{i}$ : residual

\section{FUNGSI LIKELIHOOD MODEL TOBIT}

Misalkan $X_{1}, X_{2}, \ldots, X_{n}$ merupakan variabel acak dengan fungsi peluang bersama $f\left(X_{1}, X_{2}, \ldots, X_{n} ; \theta\right)$. Maka fungsi likelihoodnya sebagai berikut:

$$
\begin{aligned}
f\left(X_{1}, X_{2}, \ldots, X_{n} ; \theta\right) & =f\left(X_{1} ; \theta\right) . f\left(X_{2} ; \theta\right) . \ldots . f\left(X_{n} ; \theta\right) \\
& =\prod_{i=1}^{n} f\left(X_{i} ; \theta\right)
\end{aligned}
$$

dimana fungsi likelihood dinotasikan dengan $L(\theta)$.

Fungsi likelihood dari model tobit [6] adalah :

$$
\begin{aligned}
& L=\prod_{y_{i}=0}^{n_{0}} P\left(Y, y_{i}=0\right) \prod_{y_{i}>0}^{n_{1}} P\left(Y, y_{i}>0\right) \\
& L=\prod_{y_{i}=0}^{n_{0}}\left[1-\Phi\left(\frac{x_{i}^{\prime} \beta}{\sigma}\right)\right] \prod_{y_{i}>0}^{n_{0}} \sigma^{-1} \phi\left[\left(\frac{y_{i}-x_{i}^{\prime} \beta}{\sigma}\right)\right]
\end{aligned}
$$

dimana:

$\prod_{y_{i}=0}^{n_{0}}$ : perkalian dari banyaknya pengamatan dimana $y_{i}=0$ atau $y_{i}{ }^{*} \leq 0$

$\prod_{y_{i}>0}^{n_{1}}$ : perkalian dari banyaknya pengamatan dimana $y_{i}>0$ atau $y_{i}{ }^{*}>0$

$n_{0}=$ banyaknya pengamatan dimana $y_{i}=0$

$n_{1}=$ banyaknya pengamatan dimana $y_{i}>0$

\section{ESTIMASI PARAMETER MODEL TOBIT}

Estimasi parameter adalah suatu metode untuk mengetahui sekitar nilai-nilai suatu populasi dengan menggunakan nilai-nilai sampel. Metode yang digunakan untuk menduga parameter dalam regresi tobit adalah metode maximum likelihood.

$$
\begin{aligned}
& L=\prod_{y_{i}=0}^{n_{0}}\left[1-\Phi\left(\frac{x_{i}^{\prime} \beta}{\sigma}\right)\right] \prod_{y_{i}>0}^{n_{0}} \sigma^{-1} \phi\left[\left(\frac{y_{i}-x_{i}^{\prime} \beta}{\sigma}\right)\right] \\
& \ln L=\sum_{y_{i}=0}^{n_{0}} \ln \left[1-\Phi\left(\frac{x_{i}^{\prime} \beta}{\sigma}\right)\right]+\sum_{y_{i}>0}^{n_{1}} \ln \left[\frac{1}{\sigma \sqrt{2 \pi}} e^{-\frac{1}{2 \sigma^{2}}\left(y_{i}-x_{i}^{\prime} \beta\right)^{2}}\right]
\end{aligned}
$$


dimana:

$\sum_{y_{i}=0}^{n_{0}}$ : perkalian dari banyaknya pengamatan dimana $y_{i}=0$

$\sum_{y_{i}>0}^{n_{1}}$ : perkalian dari banyaknya pengamatan dimana $y_{i}>0$

misalkan:

$n_{0}$ : banyaknya pengamatan dimana $y_{i}=0$

$n_{1}$ : banyaknya pengamatan dimana $y_{i}>0$

dengan $n_{0}+n_{1}=n$

suku terakhir dari Persamaan (5)

$$
\begin{aligned}
& \sum_{y_{i}>0}^{n_{1}} \ln \left[\frac{1}{\sigma \sqrt{2 \pi}} e^{-\frac{1}{2 \sigma^{2}}\left(y_{i}-x_{i}^{\prime} \beta\right)^{2}}\right] \\
& =-n_{1} \ln \sigma-\frac{n_{1}}{2} \ln (2 \pi)-\frac{1}{2 \sigma^{2}} \sum_{y_{i}>0}^{n_{1}}\left(y_{i}-x_{i}^{\prime} \beta\right)^{2} \\
& =-\frac{n_{1}}{2} \ln \sigma^{2}-\frac{n_{1}}{2} \ln (2 \pi)-\frac{1}{2 \sigma^{2}} \sum_{y_{i}>0}^{n_{1}}\left(y_{i}-x_{i}^{\prime} \beta\right)^{2}
\end{aligned}
$$

Substitusikan Persamaan (6) ke Persamaan (5)

$\ln L=\sum_{y_{i}=0}^{n_{0}} \ln \left[1-\Phi\left(\frac{x_{i}^{\prime} \beta}{\sigma}\right)\right]-\frac{n_{1}}{2} \ln \sigma^{2}-\frac{n_{1}}{2} \ln (2 \pi)-\frac{1}{2 \sigma^{2}} \sum_{y_{i}>0}^{n_{1}}\left(y_{i}-x_{i}^{\prime} \beta\right)^{2}$

Untuk mencari nilai ekstrimnya misalkan $\frac{\partial \ln L}{\partial \beta}=0$ dan $\frac{\partial \ln L}{\partial \sigma^{2}}=0$, maka

$$
\begin{aligned}
& 0=-\frac{1}{\sigma} \sum_{y_{i}=0}^{n_{0}} \frac{\phi\left(\frac{x_{i}^{\prime} \beta}{\sigma}\right) x_{i}^{\prime}}{1-\Phi\left(\frac{x_{i}^{\prime} \beta}{\sigma}\right)}+\frac{1}{\sigma^{2}}\left(y_{i}-x_{i}^{\prime} \beta\right) x_{i}^{\prime} \\
& 0=-\frac{1}{2 \sigma^{3}} \sum_{y_{i}=0}^{n_{0}} \frac{\left(x_{i}^{\prime} \beta\right) \phi\left(\frac{x_{i}^{\prime} \beta}{\sigma}\right)}{1-\Phi\left(\frac{x_{i}^{\prime} \beta}{\sigma}\right)}-\frac{n_{1}}{2 \sigma^{2}}+\frac{1}{2 \sigma^{4}} \sum_{y_{i}>0}^{n_{1}}\left(y_{i}-x_{i}^{\prime} \beta\right)^{2}
\end{aligned}
$$

Dengan menyelesaikan Persamaan (7) dan Persamaan (8) maka akan diperoleh penaksir $\beta$ dan $\sigma^{2}$. Untuk mendapatkan penaksir dari $\sigma^{2}$, kalikan Persamaan (7) dengan $\frac{\beta}{2 \sigma^{2}}$ dan tambahkan dengan Persamaan (8) akan didapatkan:

$$
\begin{aligned}
\sigma^{2} & =\frac{\sum_{y_{i}>0}^{n_{1}}\left(y_{i}-x_{i}^{\prime} \beta\right) y_{i}}{n_{1}} \\
\beta & =\left(X_{1}^{\prime} X_{1}\right)^{-1} X_{1}^{\prime} Y_{1}-\sigma\left(X_{1}^{\prime} X_{1}\right)^{-1} X_{0}^{\prime} \gamma_{0} \\
& =\beta_{L S}-\sigma\left(X_{1}^{\prime} X_{1}\right)^{-1} X_{0}^{\prime} \gamma_{0}^{\prime}
\end{aligned}
$$

\section{UJI SIGNIFIKANSI PARAMETER}

Uji signifikansi parameter digunakan untuk mengetahui ada tidaknya hubungan parameter didalam model regresi. Uji signifikansi paramater terdiri dari dua tahapan, yaitu uji signifikansi parameter secara simultan dan uji signifikansi parameter secara parsial.

1. Uji signifikansi parameter secara simultan bertujuan untuk mengetahui pengaruh variabel bebas secara bersama-sama dan diuji menggunakan likelihood rasio. Hipotesis yang digunakan:

$H_{0}: \beta_{i}=0, i=1,2, \ldots, 5$

$H_{1}$ : minimal ada salah satu $\beta_{i}$ yang tidak sama dengan nol , $i=1,2, \ldots, 5$

$H_{0}$ ditolak jika nilai $p-$ value $<\alpha$ yang berarti ada salah satu atau lebih $\beta i$ yang berpengaruh signifikan terhadap variabel terikat.

2. Uji signifikansi parameter secara parsial dilakukan untuk menguji setiap $\beta_{j}$ secara individual untuk menunjukan apakah suatu variabel bebas layak untuk masuk dalam model. Untuk mengujinya digunakan wald test. 
Hipotesis:

$H_{0}: \beta_{j}=0$ (koefisien $\beta_{j}$ tidak signifikan secara statistik)

$H_{1}: \beta_{j} \neq 0$, untuk $j=1,2, \ldots, p$ (koefisien $\beta_{j}$ signifikan secara statistik)

Statistik uji yang digunakan adalah:

$$
W=\frac{\widehat{\beta_{J}}}{\operatorname{SE}\left(\widehat{\beta_{J}}\right)}
$$

dimana:

$\widehat{\beta_{J}}=$ penduga parameter $\beta_{j}$

$\operatorname{SE}\left(\widehat{\beta}_{J}\right)=$ standard error dari $\beta_{j}$

Statistik uji ini berdistribusi chi-kuadrat dengan derajat bebas k-1 atau ditulis $W \sim \chi_{\alpha,(k-1)}^{2} . H_{0}$ ditolak jika nilai $W>\chi_{\alpha,(k-1)}^{2}$ dengan $\alpha$ adalah tingkat signifikansi yang dipilih. Bila $H_{0}$ ditolak artinya parameter tersebut signifikan secara statistik pada tingkat signifikansi $\alpha$.

\section{PENENTUAN KESESUAIAN MODEL}

Kriteria kesesuaian model pada regresi Tobit dapat dianalisis dengan menggunakan metode AIC dan menentukan nilai koefisien determinasi $\left(R^{2}\right)$.

1. Metode AIC dilakukan dengan membandingkan semua kemungkinan model yang bisa terbentuk dari variabel bebas yang membentuk model. Metode AIC adalah metode yang dikembangkan oleh Hirotsugu Akaike pada tahun 1974. AIC tidak melakukan pengujian untuk satu model saja, tetapi dengan membandingkan antara beberapa model sehingga diperoleh model yang terbaik [7]. Bentuk umum metode AIC:

$$
A I C=-2 \ln (L)+2 k
$$

dimana:

$L=$ nilai maksimum dari fungsi likelihood

$k=$ banyaknya parameter dalam model.

Model yang terbaik menurut AIC adalah model yang memberikan nilai AIC terkecil diantara model yang lain.

2. Menentukan kesesuaian model dalam analisis regresi salah satunya dapat menggunakan koefisien determinasi $R^{2}$. Besarnya nilai koefisien determinasi $R^{2}$ ini umumnya berkisar antara $0-1$, semakin kecil nilai koefisien determinasi $R^{2}$, maka artinya pengaruh variabel bebas terhadap variabel terikat semakin lemah. Penentuan kesesuaian model didasarkan pada besarnya nilai $R^{2}$. Berikut persamaan $R^{2}$ untuk regresi Tobit:

$$
R^{2}=1-\frac{\sum_{i=1}^{n} \widehat{u_{l}^{2}}}{\sum_{i=1}^{n}\left(Y_{i}-\bar{Y}\right)^{2}}
$$

\section{ASURANSI}

Definisi asuransi di Indonesia telah ditetapkan dalam UU No.2 Tahun 1992. Asuransi adalah perjanjian antara dua pihak atau lebih, dengan mana pihak penanggung mengikat diri kepada tertanggung, dengan menerima premi asuransi, untuk memberikan penggantian kepada tertanggung karena kerugian, kerusakan, kehilangan keuntungan yang diharapkan atau yang biasa disebut klaim.

Menurut [8] pengertian klaim adalah suatu permintaan salah satu dari dua pihak yang mempunya ikatan, agar haknya terpenuhi. Satu dari dua pihak yang melakukan ikatan tersebut akan mengajukan klaimnya kepada pihak lainnya sesuai dengan perjanjian atau polis yang disepakati bersama oleh kedua pihak.

\section{STUDI KASUS}

Data dalam penelitian ini berupa data besar klaim sebagai variabel terikat, dengan nilai variabel terikat 0 dan nilai sebenarnya. Sedangkan variabel bebas pada penelitian ini adalah faktor-faktor yang 
memengaruhi besar klaim asuransi, yaitu produk asuransi $\left(\mathrm{X}_{1}\right)$, cara pembayaran premi $\left(\mathrm{X}_{2}\right)$, masa asuransi $\left(\mathrm{X}_{3}\right)$, besar premi $\left(\mathrm{X}_{4}\right)$, dan masa pembayaran premi $\left(\mathrm{X}_{5}\right)$. Data yang digunakan adalah data pada tahun 2005-2015 yang berjumlah 3872 .

Pertama, dilakukan estimasi model awal regresi Tobit yang dibentuk dari 5 variabel bebas. Hasil estimasi dapat dilihat pada Tabel 1 berikut:

Tabel 1 Estimasi Dugaan Awal Model

\begin{tabular}{lrr}
\hline Variabel & Coefficient & Std. Error \\
\hline Produk Asuransi $\left(\mathrm{X}_{1}\right)$ & $-3.937 .260,00$ & $853.383,00$ \\
Cara Pembayaran Premi $\left(\mathrm{X}_{2}\right)$ & $-75.454,04$ & $1.562 .651,00$ \\
Masa Asuransi $\left(\mathrm{X}_{3}\right)$ & $-1.155 .260,00$ & $990.680,40$ \\
Besar Premi $\left(\mathrm{X}_{4}\right)$ & $-0,079874$ & 0,076159 \\
Masa Pembayaran Premi $\left(\mathrm{X}_{5}\right)$ & $-981.152,20$ & $1.139 .788,00$ \\
$\mathrm{C}$ & $-41.102 .428,00$ & $1.218 .335,00$ \\
\hline Sumber: Hasil olah E-views & &
\end{tabular}

Berdasarkan Tabel 1 diperoleh model dugaan awal regresi tobit sebagai berikut: $Y^{*}=-41.102 .428-3.937 .260,0 \mathrm{X}_{1}-75.454,04 \mathrm{X}_{2}-1.155 .260,0 \mathrm{X}_{3}-0,079874 \mathrm{X}_{4}-981.152,2 \mathrm{X}_{5}$

Selanjutnya, dilakukan uji signifikansi parameter secara simultan yang bertujuan untuk mengetahui pengaruh variabel bebas secara bersama-sama dan diuji menggunakan likelihood rasio. Hipotesis yang digunakan:

$H_{0}: \beta_{i}=0, i=1,2, \ldots, 5$

$H_{1}$ : minimal ada salah satu $\beta i$ yang tidak sama dengan nol , $i=1,2, \ldots, 5$

$H_{0}$ ditolak jika nilai $p-$ value $<\alpha$ yang berarti ada salah satu atau lebih $\beta i$ yang berpengaruh signifikan terhadap variabel terikat.

Tabel 2 Uji Signifikansi Parameter Secara Simultan

\begin{tabular}{lrll}
\hline Redundant Variables: $\mathrm{X}_{1} \mathrm{X}_{2} \mathrm{X}_{3} \mathrm{X}_{4} \mathrm{X}_{5}$ & Value & $\mathrm{df}$ & Probability \\
\hline Likelihood ratio & $8.345,63$ & 5 & 0,0000 \\
\hline Sumber: Hasil olah E-views & &
\end{tabular}

Tabel 2 menunjukkan nilai likelihood ratio sebesar 8.345,63 dengan probabilitas sebesar 0,0000. Apabila dibandingkan dengan nilai tabel distribusi Chi-kuadrat dengan taraf signifikansi $\alpha=0,05$ dan derajat bebas 5, maka nilai likelihood ratio lebih besar dari nilai tabel Chi-kuadrat $\left(\chi_{(0,05 ; 5)}{ }^{2}=\right.$ 11,07048). Keputusan yang diambil adalah menolak $H_{0}$, sehingga minimal ada satu atau lebih variabel bebas yang memengaruhi besar klaim asuransi jiwa.

Setelah melakukan uji signifikansi parameter secara simultan, selanjutnya dilakukan uji signifikansi parameter secara parsial dengan wald test. Wald test dilakukan untuk melihat peranan masing-masing variabel bebas terhadap variabel terikat. Hipotesis yang digunakan:

$H_{0}: \beta_{i}=0$ (koefisien $\beta_{i}$ tidak signifikan secara statistik)

$H_{1}: \beta_{i} \neq 0$, untuk $i=1,2,3,4,5$ (koefisien $\beta_{i}$ signifikan secara statistik)

$H_{0}$ ditolak jika nilai statistik uji $W>\chi_{\alpha,(k-1)}^{2}$ atau jika $p-$ value $<\alpha$ yang berarti $\beta_{i}$ berpengaruh signifikan terhadap variabel terikat. 
Tabel 3 Uji Signifikansi Parameter Secara Parsial

\begin{tabular}{lrr}
\hline Variabel & Coefficient & Prob. \\
\hline Produk Asuransi $\left(\mathrm{X}_{1}\right)$ & $-3.937 .260,00$ & 0,0000 \\
Cara Pembayaran Premi $\left(\mathrm{X}_{2}\right)$ & $-75.454,04$ & 0,9615 \\
Masa Asuransi $\left(\mathrm{X}_{3}\right)$ & $-1.155 .260,00$ & 0,2436 \\
Besar Premi $\left(\mathrm{X}_{4}\right)$ & $-0,079874$ & 0,2943 \\
Masa Pembayaran Premi $\left(\mathrm{X}_{5}\right)$ & $-981.152,20$ & 0,3893 \\
$\mathrm{C}$ & $-41.102 .428,00$ & 0,0007 \\
\hline Sumber: Hasil olah E-views & &
\end{tabular}

Berdasarkan Tabel 3 variabel bebas cara pembayaran premi $\left(\mathrm{X}_{2}\right)$, masa asuransi $\left(\mathrm{X}_{3}\right)$, besar premi $\left(\mathrm{X}_{4}\right)$, dan masa pembayaran premi $\left(\mathrm{X}_{5}\right)$ memiliki nilai probabilitas yang lebih besar dari $\alpha=0,05$. Hal ini berakibat bahwa variabel-variabel tersebut tidak berpengaruh secara signifikan terhadap variabel Y (besar klaim). Oleh karena itu, variabel bebas yang tidak signifikan dikeluarkan dari model satu per satu, dimulai dari yang memiliki nilai probabilitas paling besar untuk selanjutnya diuji kembali hingga ditemukan model dengan variabel bebas yang signifikan atau variabel bebas dengan nilai probabilitas kurang dari $\alpha=0,05$.

Variabel bebas cara pembayaran premi $\left(\mathrm{X}_{2}\right)$ memiliki nilai probabilitas paling tinggi, maka variabel bebas $\mathrm{X}_{2}$ merupakan variabel bebas pertama yang dikeluarkan dari model.

Tabel 4 Uji Signifikansi Parameter Model Kedua

\begin{tabular}{lrr}
\hline Variabel & Coefficient & Prob. \\
\hline Produk Asuransi $\left(\mathrm{X}_{1}\right)$ & $-3.938 .028,00$ & 0,0000 \\
Masa Asuransi $\left(\mathrm{X}_{3}\right)$ & $-1.149 .740,00$ & 0,2427 \\
Besar Premi $\left(\mathrm{X}_{4}\right)$ & $-0,080827$ & 0,2742 \\
Masa Pembayaran Premi $\left(\mathrm{X}_{5}\right)$ & $-985.399,90$ & 0,3858 \\
$\mathrm{C}$ & $-41.360 .865,00$ & 0,0002 \\
\hline Sumber: Hasil olah E-views & &
\end{tabular}

Berdasarkan Tabel 4 variabel bebas masa pembayaran premi $\left(\mathrm{X}_{5}\right)$ memiliki nilai probabilitas yang paling tinggi, maka variabel bebas kedua yang dikeluarkan dari model yaitu masa pembayaran premi $\left(\mathrm{X}_{5}\right)$. Selanjutnya, variabel bebas yang lain seperti produk asuransi $\left(\mathrm{X}_{1}\right)$, masa asuransi $\left(\mathrm{X}_{3}\right)$ dan besar premi $\left(\mathrm{X}_{4}\right)$ diuji kembali.

Tabel 5 Uji Signifikansi Parameter Model Ketiga

\begin{tabular}{lrr}
\hline Variabel & Coefficient & Prob. \\
\hline Produk Asuransi $\left(\mathrm{X}_{1}\right)$ & $-3.794 .494,00$ & 0,0000 \\
Masa Asuransi $\left(\mathrm{X}_{3}\right)$ & $-1.947 .154,00$ & 0,0000 \\
Besar Premi $\left(\mathrm{X}_{4}\right)$ & $-0,081729$ & 0,2700 \\
$\mathrm{C}$ & $-43.626 .398,00$ & 0,0000 \\
\hline Sumber: Hasil olah E-views & &
\end{tabular}

Berdasarkan Tabel 5 variabel bebas besar premi $\left(\mathrm{X}_{4}\right)$ memiliki nilai probabilitas yang paling tinggi diantara variabel bebas yang lain, maka variabel bebas ketiga yang dikeluarkan dari model yaitu variabel bebas besar premi $\left(\mathrm{X}_{4}\right)$. 
Tabel 6 Uji Signifikansi Parameter Model Keempat

\begin{tabular}{lrr}
\hline Variabel & Coefficient & Prob. \\
\hline Produk Asuransi $\left(\mathrm{X}_{1}\right)$ & $-3.826 .493,00$ & 0,0000 \\
Masa Asuransi $\left(\mathrm{X}_{3}\right)$ & $-1.818 .050,00$ & 0,0000 \\
$\mathrm{C}$ & $-45.998 .539,00$ & 0,0000 \\
\hline Sumber: Hasil olah E-views & &
\end{tabular}

Berdasarkan hasil pengujian pada Tabel 6 diperoleh variabel bebas yang signifikan dengan nilai probabilitas yang kurang dari $\alpha=0,05$ yaitu variabel produk asuransi $\left(\mathrm{X}_{1}\right)$ dan masa asuransi $\left(\mathrm{X}_{3}\right)$. Kriteria kesesuaian model pada regresi Tobit dengan menggunakan metode AIC dilakukan dengan membandingkan semua kemungkinan model yang bisa terbentuk dari variabel bebas yang membentuk model. Model yang terbaik menurut metode AIC adalah model dengan nilai AIC terendah.

Tabel 7 Nilai AIC dari Seluruh Kemungkinan Model

\begin{tabular}{lcrrc}
\hline Model & \multicolumn{2}{c}{ Nilai Koefisien } & Nilai AIC & \multicolumn{1}{c}{$\mathrm{R}^{2}$} \\
\hline 1 & $c$ & $-78.751 .889,00$ & 1,431531 & 0,00514 \\
& $x_{1}$ & $-3.858 .548,00$ & & \\
2 & $c$ & $-85.084 .469,00$ & 1,429735 & 0,00514 \\
& $x_{3}$ & $-1.790 .871,00$ & & \\
3 & $c$ & $-45.998 .539,00$ & & \\
& $x_{1}$ & $-3.826 .493,00$ & 1,424384 & 0,0176 \\
& $x_{3}$ & $-1.818 .050,00$ & & \\
\hline
\end{tabular}

Sumber: Hasil olah E-views

Nilai AIC yang ditunjukkan pada Tabel 7 memperlihatkan semua kemungkinan model yang dapat dibentuk dari variabel bebas. Dari ketiga model yang didapat, model yang terbaik menurut AIC adalah model 3, hal ini ditunjukkan oleh nilai AIC untuk model 3 terkecil yaitu 1,424384 dibandingkan dengan nilai AIC model yang lain. Berdasarkan pengujian yang dilakukan diperoleh model regresi Tobit terbaik untuk faktor yang memengaruhi besar klaim asuransi jiwa yaitu:

$$
Y^{*}=-45.998 .539-3.826 .493 \mathrm{X}_{1}-1.818 .050 \mathrm{X}_{3}
$$

Model pada persaman diatas menunjukkan bahwa semakin sedikit produk asuransi yang digunakan dan semakin pendek masa asuransi maka nilai besar klaim akan semakin kecil. Hasil pengujian kelayakan model regresi tobit dalam kasus besar klaim asuransi jiwa menunjukkan bahwa nilai $R^{2}$ yang diperoleh yaitu 0,0176. Nilai kelayakan model ini memiliki arti bahwa variabel bebas produk asuransi $\left(\mathrm{X}_{1}\right)$ dan masa asuransi $\left(\mathrm{X}_{3}\right)$ hanya dapat menjelaskan pengaruh besar klaim asuransi jiwa (Y) sebesar 1,76\% sedangkan 98,24\% lainnya dipengaruhi oleh faktor-faktor lain yang tidak terindentifikasi pada penelitian ini.

\section{KESIMPULAN}

Berdasarkan hasil dan pembahasan yang telah dilakukan, kesimpulan dari penelitian ini, yaitu:

1. Model terbaik dari analisis regresi Tobit pada data besar klaim asuransi jiwa, yaitu: $Y^{*}=-45.998 .539-3.826 .493 \mathrm{X}_{1}-1.818 .050 \mathrm{X}_{3}$.

2. Dari model terbaik yang dihasilkan, dapat dijelaskan bahwa faktor-faktor yang memengaruhi besar klaim asuransi jiwa adalah produk asuransi $\left(\mathrm{X}_{1}\right)$ dan masa asuransi $\left(\mathrm{X}_{3}\right)$. 


\section{DAFTAR PUSTAKA}

[1]. Greene WH. Econometrics Analysis 5th Edition. New Jersey: Prentice Hall; 2003.

[2]. Tobin J. Estimation of Relationships for Limited Dependent Variable. Journal Econometrica. 1958. 26(1):24-36.

[3]. Gujarati DN. Basic Econometric. $3^{\text {rd }}$ Edition. McGraw-Hill International Edition, Economic Series; 1995.

[4]. Gujarati DN. Dasar-Dasar Ekonometrika Jilid I. Jakarta: Erlangga; 2007.

[5]. Greene WH. Econometrics Analysis 6th Edition. New Jersey: Prentice Hall; 2008.

[6]. Gandhiadi GK. Model Regresi Tobit Konsumsi Susu Cair Pabrik (Studi Kasus Rumah Tangga di Provinsi Bali). E-Jurnal Matematika. 2014. 3(2):75-85.

[7]. Bozdogan, Hamparsum. Akaike's Information Criterion and Recent Develpoments in Information Complexity. Journal of Mathematical Psychology.2000; 44, 62-91.

[8]. Yaslis Ilyas. Manajemen Utilasi, Manajemen Klaim dan Kecurangan Asurani (Fraud); 2006.

ADHARTY PRATIWI SEMBIRING : Jurusan Matematika FMIPA UNTAN, Pontianak, pratiwisembiring@gmail.com 